\title{
Phenylglycidyl Ether Adducts of 2'-Deoxycytidine and 2'-Deoxyadenosine: Stability in Solution and Structure Analysis by Electrospray Tandem Mass Spectrometry
}

\author{
F. Lemière, P. Joos, K. Vanhoutte, and E. L. Esmans \\ University of Antwerp (RUCA-UIA), Nucleoside Research and Mass Spectrometry Unit, Groenenborgerlaan \\ 171, B-2020 Antwerp, Belgium
}

\author{
A. De Groot \\ University of Antwerp (RUCA), NMR Research Unit, Groenenborgerlaan 171, B-2020 Antwerp, Belgium
}

M. Claeys

Department of Pharmacy, University of Antwerp (UIA), Universiteitsplein 1, 2610.Wilrijk, Belgium

\section{E. Van den Eeckhout}

Department of Pharmacy, University of Ghent, Harelbekestraat 79, B-9000 Gent, Belgium

\begin{abstract}
The adducts of phenylglycidyl ether with 2'-deoxyadenosine (dAdo) and 2'-deoxycytidine (dCyd) exhibit structural modifications. The $\mathrm{N}-1$ adduct of dAdo underwent rearrangement to the N-6 adduct; the N-3 adduct of dCyd was deaminated to the corresponding 2'-deoxyuridine adduct. These structural modifications were studied by using liquid chromatography-electrospray tandem mass spectrometry, and kinetic data for both reactions are presented. The low energy $(+)$ collision-activated dissociation spectra of the dAdo adducts allow the two positional isomers N-1 versus N-6 to be distinguished. The structure of the latter is independently proven by an extended NMR study. For the dCyd and 2'-deoxyuridine adducts, information about the alkylation site is found in the $(-)$ collision-activated dissociation spectra. These spectra show the presence of an unexpected N-4-alkylated dCyd in addition to the two epimeric N-3 adducts. (J Am Soc Mass Spectrom 1996, 7, 682-691)
\end{abstract}

$\mathrm{I}$ nteraction of xenobiotics with DNA leads to DNA adducts that may play an important role in the misreplication of DNA and tumor formation. For several years we have been interested in adducts formed between phenylglycidyl ether (PGE) and deoxynucleosides and deoxynucleotides. PGE is an epoxide that is used in the production of epoxy resins and that shows in vitro mutagenicity against mammalian cells [1]. PGE-2'-deoxynucleoside adducts have been analyzed by fast-atom bombardment (FAB) mass spectrometry, FAB tandem mass spectrometry (FABMS/MS) [2], and by thermospray (TSP) liquid chromatography-mass spectrometry (LC-MS) [3].

During these experiments it was observed that the PGE adducts of 2'-deoxycytidine (dCyd) and 2'-deoxyadenosine (dAdo) that were initially formed underwent structural modifications in solution. In this article

Address reprint requests to Dr. E. L. Esmans, University of Antwerp (RUCA-UIA), Nucleoside Research and Mass Spectrometry Unit, Groenenborgerlaan 171, B-2020 Antwerp, Belgium. an in-depth study of these phenomena is presented. This article discusses both kinetic data of the rearrangement reactions and the electrospray (ES) mass spectrometry and tandem mass spectrometry data of the PGE adducts involved.

\section{Experimental}

\section{Instrumentation and Materials}

High-performance liquid chromatography (HPLC) separations were performed on a 5- $\mu \mathrm{m}$ Lichrosphere 60 reverse-phase select $B$ column $(125-\mathrm{mm} \times 4$-mm i.d.; Merck, Darmstadt, Germany). Phenylglycidyl ether (reagent grade)' was purchased from Merck. Methanol (HPLC grade), 2'-deoxycytidine (dCyd), 2'-deoxyadenosine (dAdo), ammonium acetate (reagent grade), and acetone- $d_{6}(99.5 \%)$ were purchased from Janssen Chimica (Beerse, Belgium). Methylene dichloride (HPLC grade) was purchased from Alltech (Applied Science Labs, Deerfield, IL). All water used was of 
Millipore (Millipore/Extrel, Pittsburgh, PA) Milli-Q quality. Electrospray (ES) spectra and single stage and tandem mass spectrometry data were acquired on a VG Quattro II triple quadrupole system (VG Analytical Ltd., Manchester, UK). The ES source was coupled to a Kontron HPLC system (Kontron Instruments, Milan, Italy) that consisted of a gradient pump system 325, HPLC 332 UV detector, and a HPLC 465 autosampler. A splitter (model Acurale ICP 20, LC Packings, Amsterdam, The Netherlands) with a split ratio of 1 to 20 was used to reduce the liquid flow that entered the ES source.

Preparative purification was done on a Novaprep 5000 HPLC system (Merck/SEPTECH) equipped with a Merck-Hitachi L-4000A UV detector. An Econosphere $10 \mathrm{RP} 18$ column $(250 \mathrm{~mm} \times 22.5 \mathrm{~mm})$ purchased from Alltech was used for these separations.

NMR spectra were recorded on a Varian Associates (Walnut Creek, CA) Unity 400 spectrometer: ${ }^{1} \mathrm{H}$ at 400 $\mathrm{MHz} ;{ }^{13} \mathrm{C}$ at $100 \mathrm{MHz}$.

\section{Reaction of Phenylglycidyl Ether with 2'-Deoxynucleosides}

To $1 \mathrm{~mL}$ of a 1-M PGE solution in methanol was added $2 \mathrm{~mL}$ of a $1-\mathrm{mg} / \mathrm{mL}$ solution of nucleoside (dCyd or $\mathrm{dAdo}$ ) in methanol. This mixture was stirred at $37^{\circ} \mathrm{C}$ in a 4-mL reacti-vial with a Teflon ${ }^{10}$-lined screw cap. After $24 \mathrm{~h}$ the sample was evaporated and the residue was redissolved in 2-mL water. The resulting inhomogeneous solution was extracted three times with 3-mL dichloromethane to remove the excess of PGE. After filtration $(0.2 \mu \mathrm{m})$ these aqueous solutions were used for all analytical studies. For the kinetic measurements, a $0.01-\mathrm{M}$ saline phosphate-buffer was used instead of water.

\section{Preparative Reaction of Phenylglycidyl Ether with 2'-Deoxyadenosine}

For preparative purposes 5-g PGE and 300-mg dAdo were dissolved in $100-\mathrm{mL}$ methanol. The reaction was done in a flask for $48 \mathrm{~h}$ at $37^{\circ} \mathrm{C}$. A HPLC run of this sample was compared to an analysis of a reaction mixture completed after $24 \mathrm{~h}$ to ensure that the prolonged reaction times had no effects other than a higher yield of adduct. The sample then was evaporated and redissolved in 100-mL water and extracted three times with $100-\mathrm{mL}$ dichloromethane. The aqueous solution was heated under reflux for $5 \mathrm{~h}$. The completion of the rearrangement reaction was checked via HPLC (column 5RP8 select B $125 \mathrm{~mm} \times 4 \mathrm{~mm}$, $35 / 65$ methanol/ammonium acetate $0.01-\mathrm{M}, 0.8$ $\mathrm{mL} / \mathrm{min}$, injected $18 \mu \mathrm{L}, \lambda=254 \mathrm{~nm})$. Compared to the unheated reaction mixture, the $\mathrm{N}-1$ adduct disappeared completely and an intense peak appeared at a retention time of approximately $21 \mathrm{~min}$. The reaction was repeated three times to produce enough rearranged adduct for an in-depth NMR study.
Preparative High-Performance Liquid Chromatography of the Rearranged Phenylglycidyl Ether-2'-Deoxyadenosine Adduct

Ten milliliter samples of the preparative reaction mixture were injected onto a 10RP18 $(250 \mathrm{~mm} \times 22.5 \mathrm{~mm})$ column and eluted by using the following program (methanol/water): $10 \mathrm{~min}$ at $40 / 60$ followed by a linear gradient to $90 / 10$ in $5 \mathrm{~min}$ and then $5-\mathrm{min}$ isocratic at 90/10. Under these circumstances the rearranged adduct eluted at approximately $17 \mathrm{~min}$ and was collected automatically by a built-in fraction collector; the rest of the sample was discarded. The combined fractions of the PGE-dAdo adduct were evaporated and lyophilized. A maximum yield of $6.5 \%$ was achieved.

\section{Liquid Chromatography, Mass Spectrometry, Tandem Mass Spectrometry Conditions}

The chromatographic conditions used were based on earlier TSP liquid chromatography-mass spectrometry (LC-MS) experiments [3], but the buffer concentration was lowered to $0.01-\mathrm{M}$ ammonium acetate. An isocratic system of 35/65 methanol/ammonium acetate at a flow rate of $0.8 \mathrm{~mL} / \mathrm{min}$ was used as the mobile phase. This composition was modified slightly as needed to optimize resolution and analysis time for each experiment. The flow was split postcolumn $(1 / 20)$, that is, $40 \mu \mathrm{L} / \mathrm{min}$ into the ES source and $760 \mu \mathrm{L} / \mathrm{min}$ to the UV detector (set at $260 \mathrm{~nm}$ ). This setup allowed us to minimize tube length and thus peak broadening. In this way also an excessive pressure buildup due to the back pressure of the splitter and a risk of damage to the UV cell was avoided. The ES source temperature was $85^{\circ} \mathrm{C}$. Tuning [distance probe tip to cone, off-axis position, bath gas flow, nebulizer gas flow, cone voltage typically $20 \mathrm{~V}$, capillary voltage $\pm 3.5 \mathrm{kV}$ for ES( + ) and $\pm 4.3 \mathrm{kV}$ for $\mathrm{ES}(-)$, skimmer voltage, collision energy, collision gas pressure] for optimal response was done on a loop injection of a $5 \times 10^{-5}-\mathrm{M}$ solution of the corresponding unmodified deoxynucleosides at the same flow-rate used during the LC-MS experiments. For the tandem mass spectrometry recordings the pressure in the collision cell was $3 \times 10^{-3}$ mbar (Ar). This corresponded to an attenuation of approximately $90 \%$ of the precursor ion abundance. The applied collision energy depended on the required fragmentation.

\section{Results and Discussion}

\section{Adducts of 2'-Deoxycytidine}

Hydrolytic Deamination of Phenylglycidyl Ether-2'-Deoxycytidine. As described earlier [3], a phenylglycidyl ether-2'-deoxyuridine (PGE-dUrd) adduct was detected in the PGE-dCyd reaction mixture. The presence of such an adduct can be explained by a hydrolytic 

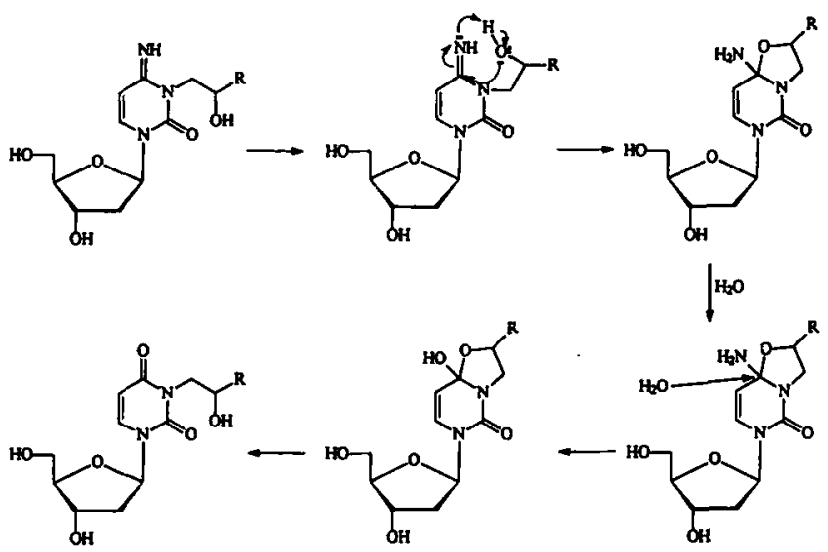

Figure 1. Hydrolytic deamination of N-3 PGE-dCyd to the corresponding N-3 PGE-dUrd adduct.

deamination reaction that involves the hydroxyl function of the PGE side chain (Figure 1).

Analogous observations have been made by other groups $[4,5]$ for the adducts formed between dCyd and propylene oxide and $\mathrm{N}$-acetoxy-4-acetamidostilbene. Because such a hydrolytic deamination reaction leads to a point mutation, we decided to study the kinetics of this reaction in detail. For that purpose the PGE-dCyd reaction mixture was redissolved in a phosphate buffer $(\mathrm{pH} 7)$ at $37^{\circ} \mathrm{C}$. Aliquots were taken at different time intervals and analyzed by HPLC UV (5RP8 select B, 35/65 methanol/ammonium acetate $0.1 \mathrm{M}, 0.8 \mathrm{~mL} / \mathrm{min}, \lambda=260 \mathrm{~nm}$ ). The peak integration of the liquid chromatography (LC) UV traces were plotted as a function of the reaction time (data not shown). At longer reaction times there is a deviation from the ideal curve. This deviation will be explained later (see Electrospray Liquid Chromatography-Tandem Mass Spectrometry of PGE-dCyd). From these results we could conclude that the reaction followed pseudo first order kinetics with a half-life time $\left(t_{1 / 2}\right)$ of $2.37 \mathrm{~h}$. A more extended study (influence of $\mathrm{pH}$ and temperature) is a subject of current research.

\section{Electrospray Mass Spectrometry of the Phenylglycidyl Ether-2'-Deoxycytidine Reaction Mixture}

ELECTROSPRAY LIQUID CHROMATOGRAPHY-MASS SPECTROMETRY. A sample of a reaction mixture of PGE with 2'-deoxycytidine was analyzed by ES( +) LC-MS (5RP8 select $B, 30 / 70$ methanol/ammonium acetate $0.1 \mathrm{M}, 0.8 \mathrm{~mL} / \mathrm{min}, \lambda=260 \mathrm{~nm}$; data not shown). Four major compounds were detected in the mixture: $\mathrm{dCyd}\left([\mathrm{MH}]^{+}, \mathrm{m} / z\right.$ 228) at $1.9 \mathrm{~min}$, two epimeric PGE-dCyd adducts ([MH] $\left.]^{+}, m / z 378\right)$ at 6.2 and 6.8 $\mathrm{min}$, and a PGE-dUrd adduct $\left([\mathrm{MH}]^{+}, m / z 379\right)$ at 9.4 $\mathrm{min}$. The ES(+) mass spectra of the different chromatographic peaks only showed protonated molecules $[\mathrm{MH}]^{+}$and their dimers $\left[\mathrm{M}_{2} \mathrm{H}\right]^{+}$. During the TSP analysis of this reaction mixture [3] the isotope peak for the protonated molecule of the PGE-dCyd adduct was noted to be more intense than expected on the basis of natural isotope abundance. This was explained by the hydrolytic deamination of PGE-dCyd ([MH $]^{+}$, $\mathrm{m} / \mathrm{z}$ 378) in the TSP source-interface to PGE-dUrd $\left([\mathrm{MH}]^{+}, m / z\right.$ 379). In the ES mass spectra such an effect was not observed. This result illustrates that this technique is more appropriate for the structural analysis of thermolabile compounds such as dCyd adducts. The reaction mixture was screened for the presence of dialkylated dCyd adducts, but no such compounds were found.

ELECTROSPRAY LIQUID CHROMATOGRAPHY-TANDEM MASS SPECTROMETRY. To get more structural information, both the positive $(+)$ and negative $(-)$ ion ES liquid chromatography-tandem mass spectrometry (LC-MS/MS) data of the PGE-dCyd reaction mixture were recorded. During the LC run, product ion scans were recorded by using different mass-to-charge ratio windows at different time intervals, which allowed us to collect all tandem mass spectrometry data of the different precursor ions $[\mathrm{MH}]^{+}$(dCyd, $m / z$ 228; PGE$\mathrm{dCyd}, m / z$ 378; PGE-dUrd, $m / z$ 379) in one run. During positive ion ES analyses a very simple fragmentation behavior was found (cf. Figure $2 a$ and b). The collision-activated dissociation (CAD) spectrum of the last eluting PGE-dCyd isomer is shown in Figure 2a. As expected for an epimer, the product ion spectrum of the first eluting isomer is identical. The protonated base moiety $\left[\mathrm{BH}+\mathrm{H}^{+}\right.$was the major product ion $(m / z 262)$, which loses water $(m / z 244)$ or phenol $(\mathrm{m} / z$ 168). Combined loss of water and phenol from the $m / z 262$ ion gives rise to a fragment ion at $m / z$ 150. Loss of the PGE side chain from the $m / z 262$ ion results in the formation of $m / z 112$. The ions at $m / z$ 133 and 105 are fragment ions of the PGE side chain.

The fragmentation pattern of the PGE-dUrd adduct $\left([\mathrm{MH}]^{+}, m / z\right.$ 379) (Figure 2b) was quite analogous to the one found for the PGE-dCyd adduct: only the relative intensities of the corresponding fragment ions were different (e.g., $m / z 168$ from PGE-dCyd versus $m / z 169$ from PGE-dUrd).

Because the fragmentation pattern observed in the positive ion ES mode gave no structural information about the exact alkylation site and because it was known [2] that during negative ion FAB-MS/MS information about the alkylation site in alkylated pyrimidines could be found, the foregoing LC-MS and LCMS/MS experiments were repeated with negative ion ES.

In the negative ion mode the spectra of the different chromatographic peaks were dominated by the $[\mathrm{M}+$ acetate $^{-}$signal (data not shown). The $[\mathrm{M}-\mathrm{H}]^{-}$ions were of much lower intensity. Because the CAD spectra of the $[\mathrm{M}+\text { acetate }]^{-}$ions primarily gave-as expected-acetate ions, the formation of deprotonated molecules had to be promoted. Therefore a coaxial flow of $1 \%$ ammonium hydroxide in methanol was added by using a triaxial electrospray probe. This addition increased the abundance of the deprotonated 


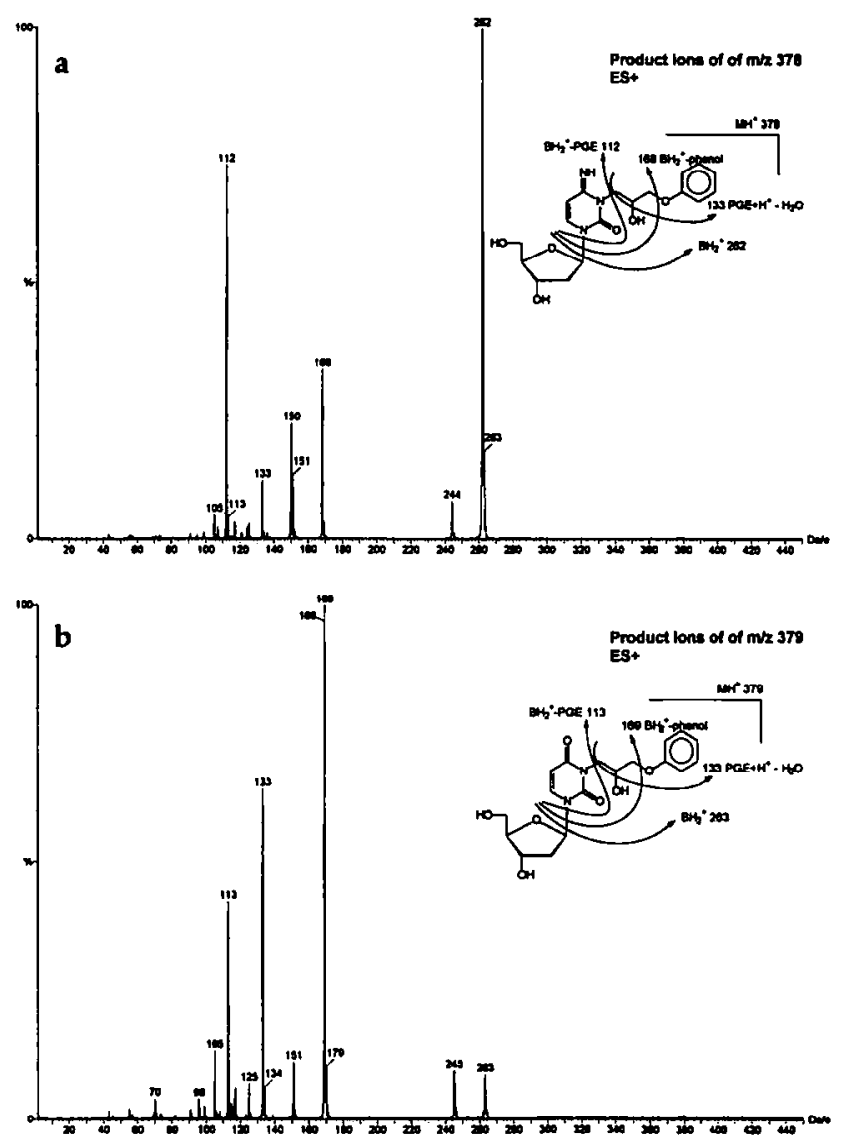

Figure 2. ES( +) CAD-MS/MS spectra of (a) PGE-dCyd ([MH] $]^{+}$, $m / z$ 378) and (b) PGE-dUrd ([MH] $]^{+}, m / z$ 379).

molecules by a factor of 2 . For all further experiments in the negative ion mode this coaxial flow was added.

Just as in the positive ion mode, this product ions ES(-) LC-MS/MS of dCyd ([M- $]^{-}, m / z$ 226), PGE-dCyd ([M - H] $]^{-}, m / z$ 376), and PGE-dUrd ([M $-\mathrm{H}]^{-}, m / z$ 377) were scanned by using different time windows (Figure 3a).

The fragmentation pattern of dCyd (Figure $3 \mathrm{~b}$ ) and the PGE adducts are summarized and explained in Table 1. When the CAD spectra of the PGE-dCyd adducts that elute at 6.2 (Figure $3 \mathrm{c}$ ) and $6.8 \mathrm{~min}$ (Figure $3 d$ ) were analyzed, some differences were observed. Indeed, the CAD spectrum of the compound that elutes at $6.2 \mathrm{~min}$ showed ions that could be characteristic for an N-4-alkylated dCyd (see Figure 4), that is $m / z 243$ (loss of HOCN and cleavage of the sugar moiety) and $m / z 42$ (isocyanate) that result from a retro Diels-Alder cleavage. The presense of these ions indicates a dCyd compound singly adducted at position $N-4$. The ion at $m / z$ 183, however, points to an alkylation at position $\mathrm{N}-3$.

To solve this contradiction several data files that contain the analysis of several PGE-dCyd reactions were compared by looking at the reconstructed ion chromatograms for $m / z 243$ and 42 and the total ion current (TIC) of the production of $\mathrm{m} / z 377$ (data not shown). Then it became clear that a small shift existed between the maxima of $m / z 243$ and 42 (N-4 alkylation) and the TICs (N-3 alkylation). Therefore we concluded that a third PGE-dCyd adduct was present in the reaction mixture, with the PGE attached to the exocyclic $N-4$. This also explains the presence of small peak at $t_{\mathrm{R}}= \pm 6.2 \mathrm{~min}$ after complete deamination of the two epimeric N-3 adducts because the N-4 adducts are not susceptible to a hydrolytic deamination reaction. This hypothesis was confirmed by the analysis of a PGE-dCyd mixture that was warmed up for $24 \mathrm{~h}$ to $60^{\circ} \mathrm{C}$. In such a mixture the N-3 PGE-adduct is deaminated to the N-3 PGE-dUrd adduct (Figure 3e), which allows the tandem mass spectrometry data of the pure N-4 PGE-dCyd isomer to be recorded. The corresponding product ion spectrum is depicted in Figure 4. Comparison of Figure $3 \mathrm{~d}$ and Figure 4 clearly shows that differentiation between N-3 and N-4 PGE-dCyd is possible under negative ion electrospray ionizationtandem mass spectrometry (ES-MS/MS) conditions. To our knowledge no other epoxide adducts on N-4 of $\mathrm{dCyd}$ are described in the literature.

\section{Adducts of 2'-Deoxyadenosine}

Rearrangement of N-1 Phenylglycidyl Ether-2'-Deoxyadenosine. As we reported earlier, the reaction mixture of PGE with dAdo contained a second monoalkylated nucleoside [3]. When dAdo is reacted with PGE, the first adduct formed is the $\mathrm{N}-1$ adduct as shown by Van den Eeckhout et al. [6].

If the structure of the PGE-dAdo adduct alkylated at the N-1 position is compared with the structure of the N-3 adduct of dCyd a similar hydrolytic deamination reaction of the imine function may be expected. This should lead to the N-1-alkylated inosine. To check this hypothesis, a reaction mixture of PGE with dAdo was kept at a $60^{\circ} \mathrm{C}$ for $24 \mathrm{~h}$. UV HPLC analyses (5RP8 select $B$ column, 35/65 methanol/ammonium acetate $0.1 \mathrm{M}, 0.8 \mathrm{~mL} / \mathrm{min}, \lambda=260 \mathrm{~nm}$ ) of the reaction mixture, before and after heating, showed a decrease of the $\mathrm{N}-1$ adduct $\left(t_{\mathrm{R}}=3.7 \mathrm{~min}\right)$. At the same time a new compound eluted at $t_{\mathrm{R}}=11.6 \mathrm{~min}$, with a concentration that gradually increased with time. To check whether a 2'-deoxyinosine adduct was formed, the analysis of both samples was repeated with thermospray mass spectrometry detection [3]. Unexpectedly, the $\mathrm{N}-1$ adduct of deoxyinosine $\left([\mathrm{MH}]^{+}, m / z\right.$ 403) was not found; rather, an unidentified alkylated dAdo ([MH] $]^{+}, m / z$ 402) was found.

To explain these observations a Dimroth rearrangement [5] was proposed during which the $\mathrm{N}-1$ adduct was transformed into the exocyclic N-6 adduct, but no structural evidence was apparent.

In view of the foregoing results the PGE-dAdo mixture was reinvestigated by ES( +) mass spectrometry and tandem mass spectrometry. Furthermore the kinetics of the reaction were studied and the adduct was isolated on a preparative scale by HPLC to study the compound by NMR. 

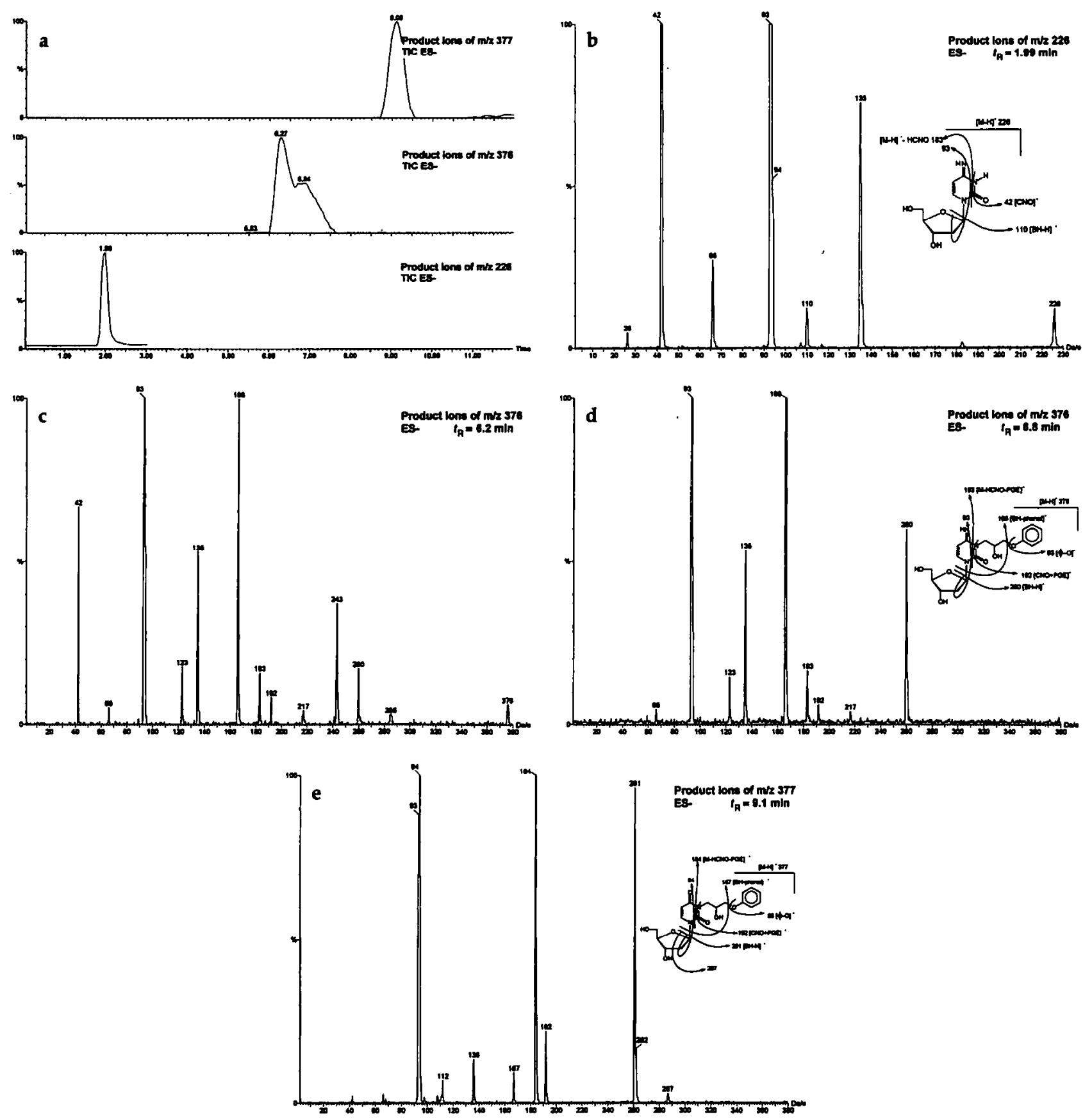

Figure 3. (a) Reconstructed ion chromatograms ES( - ) of the product ions of dCyd $(m / z$ 226), PGE-dCyd, and PGE-dUrd ( $m / z$ 379) and the combined product ion spectra of the different chromatographic signals: (b) dCyd, $t_{R}=1.99$ min, (c) N-3 PGE-dCyd (epimer 1), $t_{R}=6.2 \mathrm{~min}$ with some fragments typical for N-4 alkylation, (d) N-3 PGE-dCyd (epimer 2), $t_{R}=6.8 \mathrm{~min}$, and (e) N-3 PGE-dUrd, $t_{\mathrm{R}}=9.1 \mathrm{~min}$.

After the crude isolation of the reaction mixture (see Experimental) the mixture was redissolved in phosphate buffer $\left(\mathrm{pH} 7,37^{\circ} \mathrm{C}\right)$ and was sampled over two days. The peak integration of the LC UV traces was plotted as a function of the reaction time (Figure 5). As expected for a Dimroth rearrangement first order kinetics was observed with a half-life time $t_{1 / 2}=$ $20.78 \mathrm{~h}$.
Electrospray Mass Spectrometry of the Phenylglycidyl Ether-2'-Deoxyadenosine Reaction Mixture

ELECTROSPRAY LIQUID CHROMATOGRAPHY-MASS SPECTROMETRY. A PGE-dAdo reaction mixture was analyzed by ES + +)-LC-MS before and after the mixture was heated. These data confirm the TSP results. In the PGE-dAdo reaction mixtures, three PGE adducts were 
Table 1. Product ions of dCyd, PGE-dCyd, and PGE-dUrd

\begin{tabular}{|c|c|c|c|c|}
\hline \multicolumn{4}{|c|}{ Product mass-to-charge ratio } & \multirow[b]{2}{*}{ Origin } \\
\hline $\begin{array}{c}\mathrm{dCyd} \\
m / z 226 \\
t_{\mathrm{R}}=1.9 \mathrm{~min}\end{array}$ & $\begin{array}{c}\text { PGE-dCyd } \\
m / z 376 \\
t_{\mathrm{R}}=6.8 \mathrm{~min}\end{array}$ & $\begin{array}{c}\text { PGE-dCyd } \\
m / z 376 \\
t_{\mathrm{R}}=6.2 \mathrm{~min}\end{array}$ & $\begin{array}{c}\text { PGE-dUrd } \\
m / z 377 \\
t_{\mathrm{R}}=9.1 \mathrm{~min}\end{array}$ & \\
\hline 226 & 376 & 376 & 377 & Precursor \\
\hline $183(R=H)$ & $183(R=P G E)$ & $183(R=P G E)$ & $184(R=P G E)$ & Retro DA, loss of RCNO \\
\hline 135 & 135 & 135 & 136 & Retro DA + loss of $\mathrm{H}_{2} \mathrm{O}$ and $\mathrm{CH}_{2} \mathrm{O}$ \\
\hline 110 & 260 & 260 & 261 & Base moiety, loss of sugar \\
\hline \multirow[t]{2}{*}{93} & & & & Retro DA loss of HCNO + cleavage of sugar \\
\hline & 93 & 93 & 94 & $\begin{array}{l}\text { Retro DA loss of (HCNO + PGE side chain) } \\
\text { +cleavage of sugar }\end{array}$ \\
\hline \multirow[t]{2}{*}{42} & & 42 & & Retro $\mathrm{DA}, \mathrm{CNO}^{-}$ \\
\hline & 192 & 192 & 192 & Retro DA, $\mathrm{CNO}^{-}+\mathrm{PGE}$ side chain \\
\hline \multirow[t]{5}{*}{26} & & & & $\mathrm{CN}^{-}$ \\
\hline & & & 287 & Cleavage of sugar \\
\hline & 166 & 166 & 167 & Loss of phenol out of base moiety \\
\hline & & 243 & & $\begin{array}{l}\text { N-4 PGE-dCyd retro DA loss of HCNO } \\
\text { +cleavage of sugar }\end{array}$ \\
\hline & 93 & 93 & 93 & Phenolate \\
\hline
\end{tabular}

"DA is Diels-Alder.

found: two nucleoside adducts $(m / z 402)$ that elute at $8.0 \mathrm{~min}$ and $12.0 \mathrm{~min}$ and an adduct of adenine (Ade; $\mathrm{m} / \mathrm{z} 286$ ) at $9.3 \mathrm{~min}$. As expected the mass spectra of each chromatographic peak contained $[\mathrm{MH}]^{+}$as the single ion at $m / z 402$ (PGE-dAdo) and 286 (PGE-Ade), respectively. No signal whatsoever was found that possibly could indicate the presence of a 2 '-deoxyinosine adduct. Therefore we concluded that the $\mathrm{N}-1$ adduct did not deaminate upon heating, but rearranged to another PGE-dAdo adduct.

The reaction mixtures were screened for dialkylated dAdo [2] but no such adducts were found.

ELECTROSPRAY LIQUID CHROMATOGRAPHY-TANDEM MASS SPECTROMETRY. To get structural information on both monoalkylated nucleosides, the samples were an-

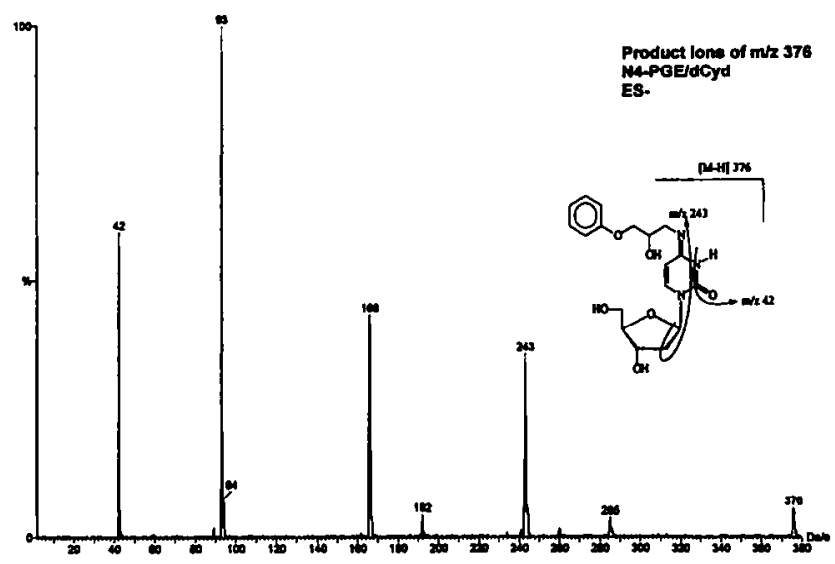

Figure 4. Product ion spectrum of N-4 PGE-dCyd with fragmentation that leads to typical product ions for $\mathrm{N}-4$ substitution indicated. alyzed by $C A D$ tandem mass spectrometry. Samples that contained the three adducts were chromatographed, which allowed all tandem mass spectrometry data to be recorded in one run. Careful turning was a prerequisite because each of the adducts was present in minute amounts. Identical LC conditions as described for LC-MS were used during LC-MS/MS runs. The total ion current traces of the products of PGEdAdo $m / z 402$ (two isomers) and PGE-Ade $m / z$ 286 are shown in Figure $6 a$ together with the CAD mass spectra of the two nucleoside adducts (Figure 6b and $c$ ).

From Figure 6 it was clear that significant differences between the spectra of both PGE-dAdo adducts

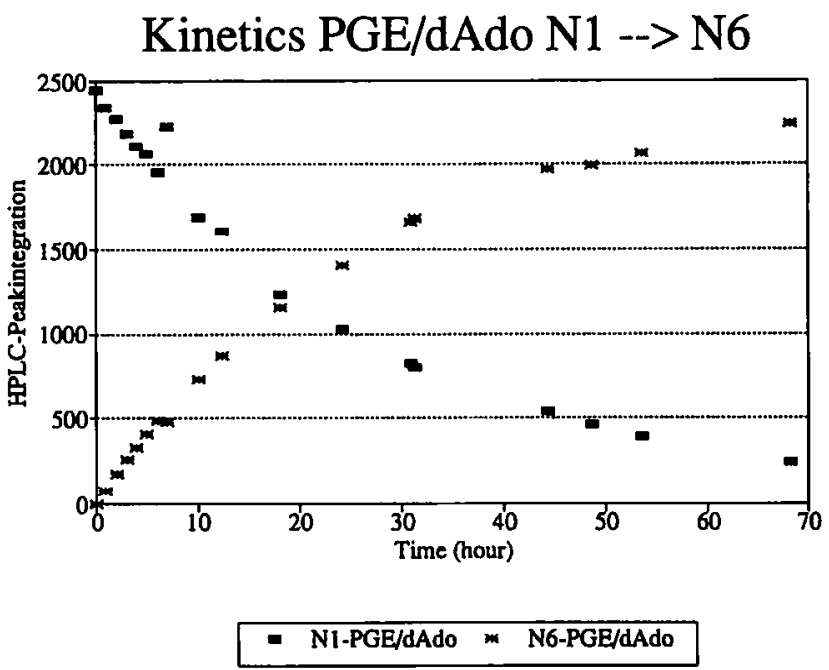

Figure 5. Peak integration versus time plot of the rearrangement of N-1 PGE-dAdo to N-6 PGE-dAdo ( $\mathrm{pH} 7,37^{\circ} \mathrm{C}$ ). 

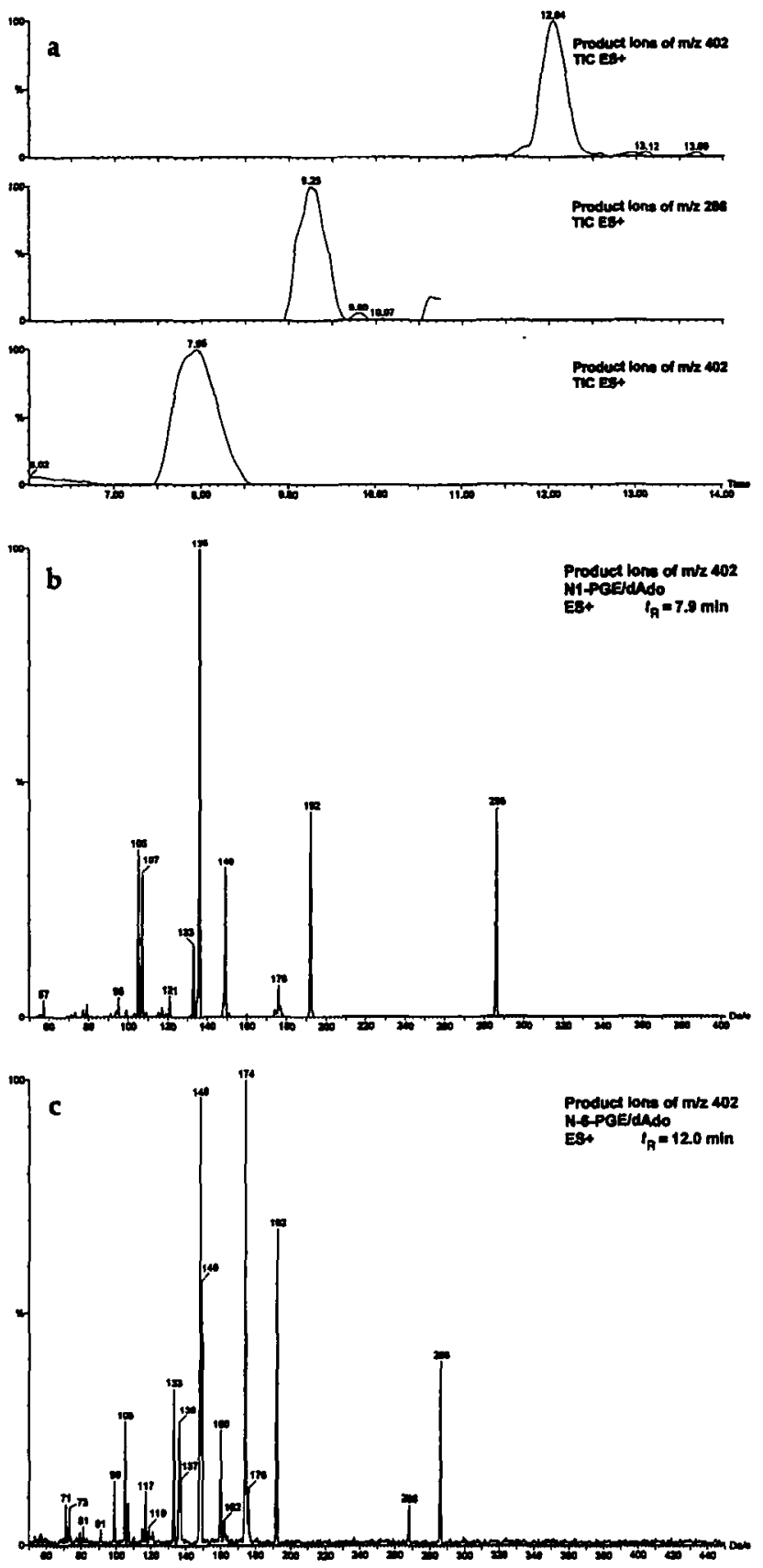

Figure 6. (a) Reconstructed ion chromatograms $E S(+)$ of the product ions of N-1 PGE-dAdo (lower trace), PGE-Ade (middle trace), and N-6 PGE-dAdo (upper trace) and the combined product ion spectra of the different chromatographic signals: (b) N-1 PGE-dAdo, $t_{\mathrm{R}}=7.9 \mathrm{~min}$, and (c) N-6 PGE-dAdo, $t_{\mathrm{R}}=12.0 \mathrm{~min}$.

were found. However some common features also were present. The product ions present in the spectra of the adducts are explained in Figures 7-9. The major differences were seen in the abundances of $m / z 136$, $148,160,174$, and 268 . The most important product ions in common for both adducts were $m / z 286$ ([BH $\left.+\mathrm{H}]^{+}\right), m / z 192\left([\mathrm{BH}+\mathrm{H}]^{+}\right.$-phenol), $m / z 136([\mathrm{BH}$ $+\mathrm{H}]^{+}$-PGE), and $m / z$ 149. The last ion remains unexplained. In [6] it was stated that $m / z 149$ originated from the PGE side chain. If this statement were correct, this product ion would be present in the product ion spectra of all PGE-nucleoside adducts, but this is not the case. Solomon et al. [5] used this fragment ion to prove N-6 alkylation of adducts formed between dAdo or Ade with propylene oxide. However the FAB CAD spectrum of the N-1 PGE-dAdo adduct described by Van den Eeckhout et al. [6] clearly shows a fragment ion at $m / z$ 149. In this case the alkylation site was assigned by using nuclear Overhauser effect NMR. Because our results agreed with both the results of Van den Eeckhout and Solomion, we concluded that $\mathrm{m} / \mathrm{z}$ 149 could not be used as a diagnostic ion for the assignment of the alkylation site in PGE-dAdo adducts.
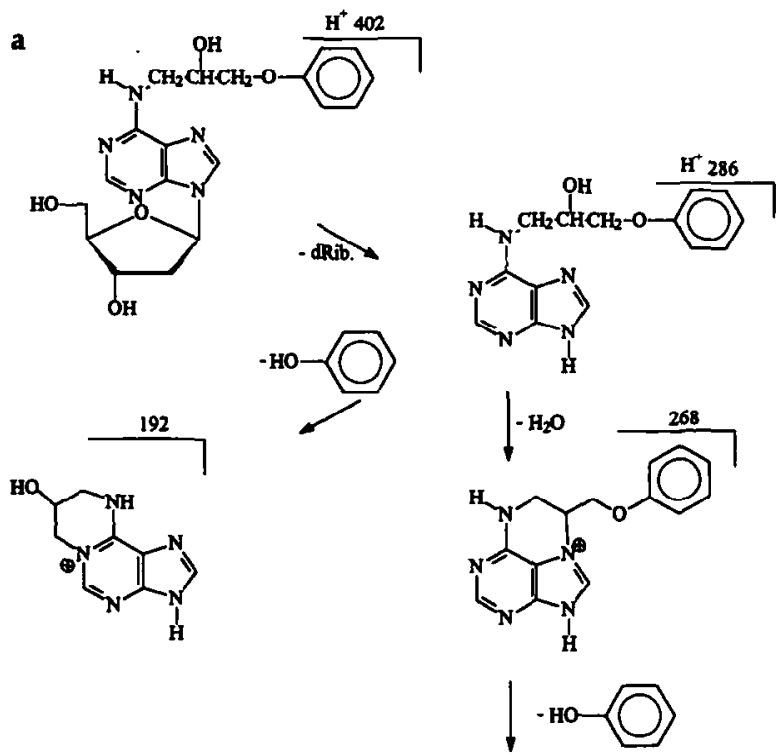<smiles>C=C1CNc2ncnc3c2N1CCC3</smiles>

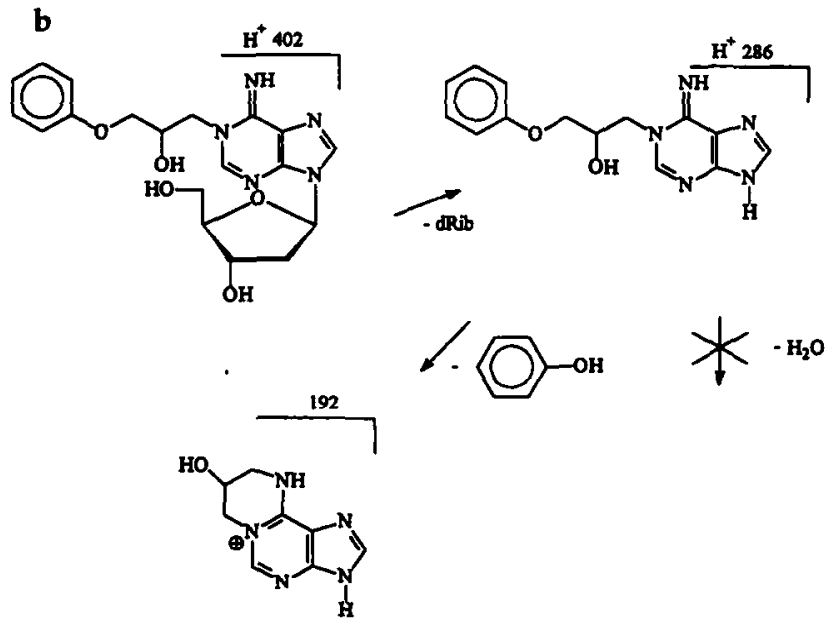

Figure 7. Fragmentation pattern for (a) N-6 PGE-dAdo and (b) N-1 PGE-dAdo. 

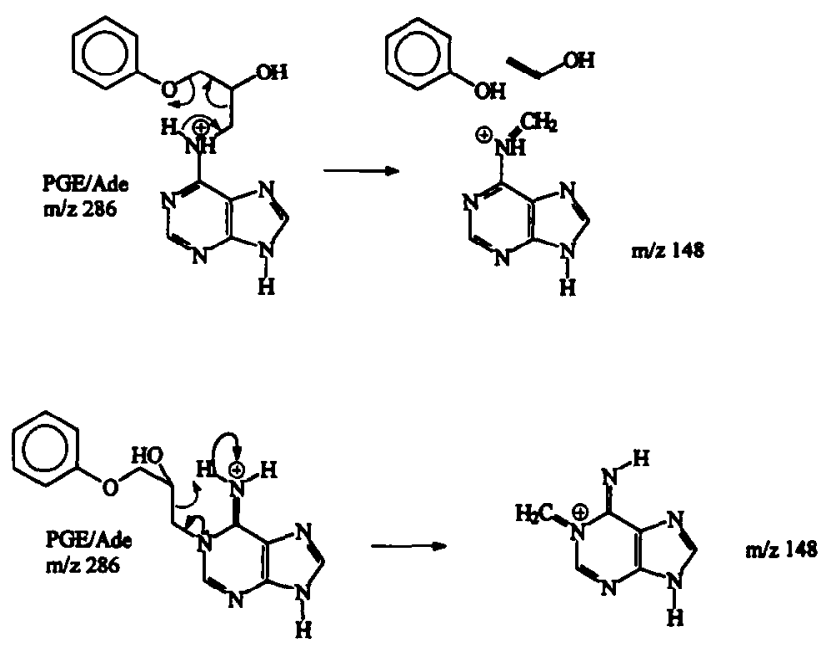

Figure 8. Possible pathways for the formation of the product ions $m / z 148$.

The product ion at $m / z 286$ is found only for the $\mathrm{N}-6$ isomer. This observation was rationalized by the stabilization of the resulting carbocation by N-7 (Figure 7a) in six-membered ring. Loss of the phenol moiety resulted in a product ion at $m / z 174$, where the cation is stabilized in an allylic system. The product ion at $m / z 148$ could be explained as a fragmentation of the side chain. Although a mechanism can be drawn for both the N-1- and N-6-isomer, only for the latter is an aromatically stablized cation formed (Figure 8). This is reflected in the difference of the relative abundance of $m / z 148$ observed in both isomers ( $\mathrm{N}-1$ : $3.43 \%$ versus $\mathrm{N}-6:$ : $95.75 \%$ ).

The ion at $m / z 136$ was assigned to protonated adenine. The loss of the PGE side chain was explained by using a McLafferty-type rearrangement. Starting from the $\mathrm{N}-6$ adduct, product ion $\mathrm{X}$ is formed (Figure 9) and the N-1 adduct yields an aromatic product ion $Y$. The difference in abundance for $m / z 136$ was then explained as a difference in stability of the product ion. From these tandem mass spectrometry data we concluded that it was possible to distinguish and rationalize the product ion spectra of the N-1 and N-6 isomeric adducts of PGE with dAdo. The adduct at $t_{\mathrm{R}}= \pm 8$ $\mathrm{min}$ is the $\mathrm{N}-1$ adduct and the adduct at $t_{\mathrm{R}}= \pm 12 \mathrm{~min}$ is alkylated at $\mathrm{N}-6$.

The electrospray source offers the possibility of cone-voltage-induced dissociation. This allows the fragmentation of the base moiety to be studied apart from the intact nucleoside. The product ion spectra of the corresponding nucleoside and base were essentially the same (data not shown).

NMR Study of N-6 Phenylglycidyl Ether-2'-Deoxyadenosine. To have an independent structure confirmation of the rearranged PGE-dAdo adduct a NMR study of the adduct was done. The adduct was isolated from a semipreparative synthesis by preparative HPLC: 14-mg adduct was obtained and was dissolved in $0.55-\mathrm{mL}$

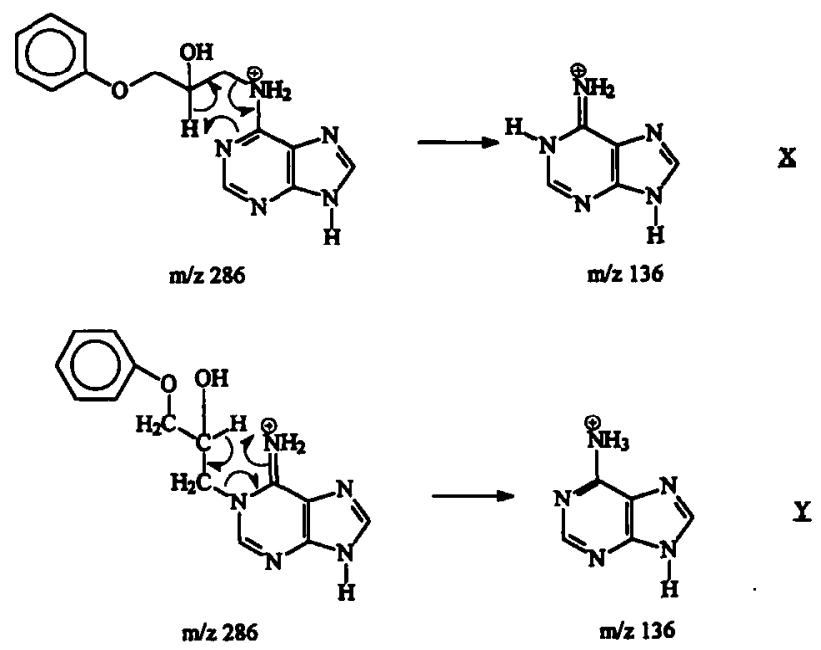

Figure 9. Rationalization of the difference in abundance of $m / z$ 136 that start from the N-6 PGE-dAdo $(X)$ and from N-1 PGEdAdo (Y).

acetone- $d_{6}$. Proton NMR spectra were recorded at 30 and $50^{\circ} \mathrm{C}$. The NMR data $\left(50^{\circ} \mathrm{C}\right)$ are summarized in Table 2. For comparison, the NMR data of 2'-deoxyadenosine and N-1 PGE-2'-deoxyadenosine [6] have been added.

To elucidate the complex coupling patterns and to be sure of the assignments of the different signals, several NMR experiments were done at varying temperatures: ${ }^{13} \mathrm{C}$, cosynchronous (COSY) two-dimensional $\left({ }^{1} \mathrm{H}_{-}{ }^{1} \mathrm{H}\right)$, and HETCOR (heterocorrelation two-dimensional $\left.{ }^{1} \mathrm{H}_{-}{ }^{13} \mathrm{C}\right)$.

A COSY two-dimensional at ambient temperature clearly showed the cross peaks for the three coupling systems, that is, the phenyl ring, the aliphatic part of the PGE chain, and the sugar moiety. This experiment showed that the complex multiplet at $4.08 \mathrm{ppm}$ was due to the combined signals of the $\mathrm{H}-4^{\prime}$ (sugar) and $\mathrm{H}-1^{\prime \prime}$ (PGE chain) protons. Although it was expected that $\mathrm{H}-2^{\prime \prime}$ would couple with $\mathrm{H}-\mathrm{1}^{\prime \prime}$ and $\mathrm{H}-3^{\prime \prime}$, the latter cross peak was missing.

The two broad bands at 3.7-4.2 ppm were expected to be the result of coalescence. Because heating in dimethyl sulfoxide (DMSO) was impossible-recovery of the nucleoside from DMSO is difficult and thermal stability is uncertain - spectra were recorded at lower temperatures, that is, $10,0-15,-30,-40$, and -70 ${ }^{\circ} \mathrm{C}$. Starting from $0{ }^{\circ} \mathrm{C}$ the broad bands gradually sharpened and finally gave a coupling pattern as expected for the geminal $\mathrm{H}-3^{\prime \prime}$ and vicinal $\mathrm{H}-3^{\prime \prime}-\mathrm{H}-2^{\prime \prime}$ protons. Optimal resolution was obtained between -30 and $-40^{\circ} \mathrm{C}$. Further cooling caused all intramolecular motions to freeze, which resulted in an increasing complexity of the coupling pattern and a decreasing signal intensity. The optimum conditions realized at $-40{ }^{\circ} \mathrm{C}$ were used in a two-dimensional experiment.

When the COSY two-dimensional experiment was repeated at $-40^{\circ} \mathrm{C}$, the $\mathrm{H}-2^{\prime \prime}$ proton coupled with $\mathrm{H}-3^{\prime \prime}$. This observation identified the signals seen ear- 
Table 2. ${ }^{1} \mathrm{H}$ NMR spectra of dAdo, N-1 PGE-dAdo, and N-6 PGE-dAdo

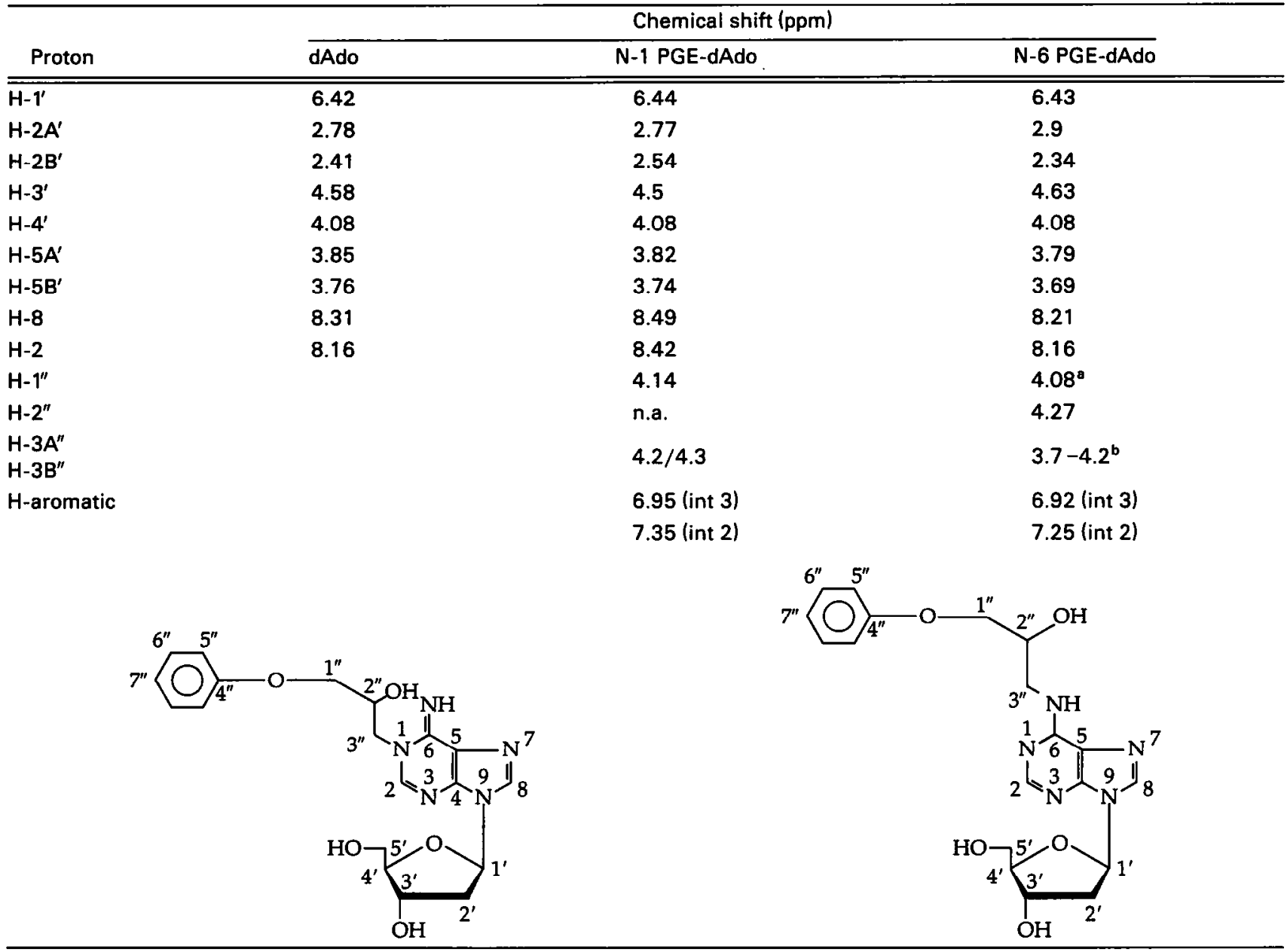

Compare to two-dimensional experiment.

b Two broad bands. Compare to COSY and low temperature.

lier as the broad bands at $3.7-4.2 \mathrm{ppm}$ as $\mathrm{H}-3^{\prime \prime}$. To check the correctness of our proton assignments a HETCOR $\left({ }^{13} \mathrm{C}-{ }^{-1} \mathrm{H}\right)$ experiment was planned. Therefore a ${ }^{13} \mathrm{C}$ spectrum of N-6 PGE-dAdo was recorded and is summarized in Table 3 . The ${ }^{13} \mathrm{C}$ NMR signals easily could be assigned, but two signals were remarkably small and broad $\left(C-3^{\prime \prime}, 44.85\right.$ ppm, and C-6, 149.304 $\mathrm{ppm}$ ). It was proposed that the process responsible for the broad bands in the ${ }^{1} \mathrm{H}$ spectra also was responsible for these weak signals in ${ }^{13} \mathrm{C}$. If this proposal is correct, sample cooling could be expected to sharpen the ${ }^{13} \mathrm{C}$ signals as was the case in the ${ }^{1} \mathrm{H}$ NMR spectrum. This assumption was correct because these signals became sharp at $-40{ }^{\circ} \mathrm{C}$. The planned HETCOR $\left({ }^{13} \mathrm{C}-{ }^{1} \mathrm{H}\right)$ experiment was recorded at $-40^{\circ} \mathrm{C}$ and showed all the expected cross peaks, which confirmed earlier assignments.

The NMR experiments described in the preceding text gave no hard proof of the alkylation site because no interactions were found between the base moiety and the side chain. However, the coincidence of the coalescence-relaxation in ${ }^{1} \mathrm{H}$ for $\mathrm{H}-3^{\prime \prime}$ and in ${ }^{13} \mathrm{C}$ for $\mathrm{C}-6$ and $\mathrm{C}-3^{\prime \prime}$ is an indication that the alkylation occurred at $\mathrm{N}-6$.
A proof for the presence of the PGE chain on the exocyclic nitrogen atom would be the existence of a coupling between the $\mathrm{H}-3^{\prime \prime}$ protons with the proton at $\mathrm{N}-6$. Hence, the sample was evaporated, lyophilized to dryness, and redissolved in dried acetone- $d_{6}(99.5 \%)$ from a freshly opened bottle. Under these conditions the ${ }^{1} \mathrm{H}$ spectrum at $-40{ }^{\circ} \mathrm{C}$ showed four additional signals at $4.9,5.8,6.35$, and $7.95 \mathrm{ppm}$ that correspond to $\mathrm{OH}-4^{\prime}, \mathrm{OH}-5^{\prime}, \mathrm{OH}-3^{\prime \prime}$, and $\mathrm{NH}-6$, respectively. However the $\mathrm{H}-3^{\prime \prime}-\mathrm{NH}-6$ coupling was too small to be observed in a one-dimensional experiment.

A two-dimensional COSY experiment revealed the following couplings: $4.9-\mathrm{ppm} \mathrm{O} 3^{\prime}-\mathrm{H} \rightarrow$ 4.63-ppm H-3'; 5.8-ppm O2"-H $\rightarrow$ 4.27-ppm H-2"; 6.35-ppm O5'-H $\rightarrow$ 3.79-ppm H-5'; 7.95-ppm N-6-H $\rightarrow 3.8$ ppm H-3" . These couplings identified the four protons on oxygen and nitrogen. The simple fact that a coupling between $\mathrm{NH}-6$ and $\mathrm{H}-3^{\prime \prime}$ was found indicated alkylation on the exocyclic nitrogen. Because the cross peak observed was rather weak, an additional experiment was done by adding a few $\mathrm{Cd}\left(\mathrm{NO}_{3}\right)_{2}$ crystals to the NMR solution (A. De Groot, unpublished results and [7]). The ${ }^{1} \mathrm{H}$ spectrum (at $30^{\circ} \mathrm{C}$ ) then showed an intense signal at $4.8 \mathrm{ppm}\left[\mathrm{OH}\right.$ signals and water from $\left.\mathrm{Cd}\left(\mathrm{NO}_{3}\right)_{2}\right]$. The 
Table 3. ${ }^{13} \mathrm{C}$ NMR spectra of dAdo and N-6 PGE-dAdo

\begin{tabular}{|c|c|c|}
\hline \multirow[b]{2}{*}{ Carbon } & \multicolumn{2}{|c|}{ Chemical shift } \\
\hline & dAdo & N-6 PGE-dAdo \\
\hline C-2 & 147.5 & 153.40 \\
\hline C-4 & 150.1 & 156.51 \\
\hline$C-6$ & 118.25 & 121.33 \\
\hline$C-6$ & 145.2 & $149.30^{\mathrm{a}}$ \\
\hline$C-8$ & 142.3 & 141.10 \\
\hline$C-1^{\prime}$ & 84.8 & 87.11 \\
\hline $\mathrm{C}-2^{\prime}$ & 39.15 & 41.59 \\
\hline$C-3^{\prime}$ & 70.9 & 73.03 \\
\hline$C-4^{\prime}$ & 87.5 & 89.88 \\
\hline$C-5^{\prime}$ & 61.4 & 63.64 \\
\hline$C-1^{\prime \prime}$ & & 71.17 \\
\hline$C-2^{\prime \prime}$ & & 70.12 \\
\hline$C-3^{\prime \prime}$ & & $44.85^{\circ}$ \\
\hline$C-4^{\prime \prime}$ & & 160.27 \\
\hline$C-5^{\prime \prime}$ & & 115.53 \\
\hline$C-6^{\prime \prime}$ & & 130.39 \\
\hline$C-7^{\prime \prime}$ & & 121.90 \\
\hline
\end{tabular}

Small and broad.

only signal that remained was the $\mathrm{NH}$ at $7.65 \mathrm{ppm}$ (change in chemical shift due to temperature difference). The signal intensity was then strong enough to enable the detection of an unmistakable cross peak in two-dimensional COSY, even at $30^{\circ} \mathrm{C}$.

From all these data we could conclude that the alkylation site in this 2'-deoxyadenosine adduct was the exocyclic N-6 as a result of a Dimroth rearrangement of the originally formed N-1 PGE-dAdo.

\section{Conclusions}

Although PGE-2'-deoxynucleoside adducts can be analyzed by TSP LC-MS, the ES LC-MS/MS data are far superior in terms of sensitivity and structural information, especially if the ES-MS system is coupled to capillary LC [8]. In this article we have demonstrated that differentiation can be made between positional isomers, that is, it is possible to determine the exact alkylation site by analyzing the low energy CAD spectra ([9] and references cited therein). This is an important feature that is often neglected in articles that discuss DNA adduct analysis by mass spectrometry. For the PGE-dAdo adducts, the most relevant data are present in ES(+)-MS/MS, whereas for the PGE-dCyd adducts ES(-)-MS/MS is the method of choice, provided the abundance of $[\mathrm{M}-\mathrm{H}]^{-}$ions is promoted by coaxial addition of ammonium hydroxide.

A NMR study was used to verify independently the alkylation site of the N-6 PGE-dAdo adduct.

\section{Acknowledgments}

We thank the NFWO for financial support (G.2133.94/G.9.008.93). P. Joos thanks the NFWO for a postdoctoral grant. K. Vanhoutte is indebted to the Flemish Institute for Promotion of ScientificTechnological Research in Industry (IWT) for a research grant.

\section{References}

1. Canter, D. A.; Zeigen, E.; Haworth, S.; Lawlor, T.; Mortelmans, K.; Speck, W. Mutation Res. 1986, 172, 105-138.

2. Claereboudt, J.; Esmans, E. L.; Van de Eeckhout, E. G.; Claeys, M. Nucleosides and Nucleotides 1990, 9, 333-344.

3. Lemière, F.; Esmans, E. L.; Van Dongen, W.; Van den Eeckhout, E.; Van Onckelen, H. J. Chromatogr. 1993, 647, 211-218.

4. Scribner, J. D.; Smith, D. L.; McCloskey, J. A. J. Org. Chem. 1978, 43, 2085-2087.

5. Solomon, J. J.; Mukai, F.; Fedyk, J.; Segal, A. Chem. Biol. Interactions 1988, 67, 257-294.

6. Van den Eeckhout, E.; de Bruyn, A.; Pepermans, H.; Esmans, E. L.; Vryens, I.; Claereboudt, J.; Claeys, M.; Sinsheimer, J. E. J. Chromatogr. 1990, 504, 113-128.

7. De Bruyn, T. Ph.D. thesis, University of Antwerp, 1995.

8. Vanhoutte, K.; Joos, P.; Lemière, F.; Van Dongen, W.; Esmans, E. L. I. Mass Spectrom. and Rapid Comm. Mass Spectrom., Joint Issue, S143-S192, 1995.

9. Wolf, S. M.; Vouros, P. Anal. Chem. 1995, 67, 891-900. 